\title{
SOCIODEMOGRAPHIC AND LIFESTYLE FACTORS IN PRE- AND POSTMENOPAUSAL PATIENTS WITH BREAST CANCER
}

José Euderaldo Costa Gomes Filho1, Ariane Silva da Rocha1, Gisele Aparecida Fernandes', Rossana Verónica Mendoza López ${ }^{1}$, Maria Paula Curado'

${ }^{1}$ AC Camargo Cancer Center - São Paulo (SP), Brazil.

To analyze pre- and postmenopausal patients with breast cancer with regard to sociodemographic factors. This is a crosssectional study with 705 patients with breast cancer. Patients aged 50 years and older accounted for $55.9 \%$ ( $\mathrm{n}=394$ ), whereas those aged 50 years or younger accounted for $44.1 \%(n=311)$. For both pre- and postmenopausal patients, there is greater proportional access through the Unified Health System (SUS), $62.7 \%(\mathrm{n}=195)$ and 51.5\% ( $\mathrm{n}=203)$ ( $\mathrm{p}=0.002)$; married, 65.9\% $(\mathrm{n}=205)$ and 52.8\% $(\mathrm{n}=208)(\mathrm{p}<0.001)$; white ethnicity, $75.9 \%(\mathrm{n}=236)$ and $77(\mathrm{n}=302)(\mathrm{p}=0.623)$; and undergraduate level, 48.1\% ( $n=149)$ and 40.1\% ( $n=158)(p<0.001)$. For $82.7 \%$ ( $n=272)$ of the SUS participants and $80.9 \%(n=276)$ of those with complementary health care $(\mathrm{p}<0.001)$, the first mammogram was performed between the ages of 18 and 40 years; own housing for $74.2 \%(\mathrm{n}=230)$ and $85.6 \%(\mathrm{n}=333)(\mathrm{p}<0.001)$, denied tobacco use, $78.1 \%(\mathrm{n}=243)$ and $64.8 \%(\mathrm{n}=254)(\mathrm{p}<0.001)$; and alcohol consumption, $76.2 \%(\mathrm{n}=237)$ and $86.2 \%(\mathrm{n}=337)(\mathrm{p}<0.001)$; the reference of cancer cases in the family occurred in $55.9 \%$ $(\mathrm{n}=118)$ and $63.7 \%(\mathrm{n}=174)(\mathrm{p}=0.300)$; however, breast cancer cases were reported in only $44.1 \%(\mathrm{n}=93)$ and $36.3 \%(\mathrm{n}=99)$ $(\mathrm{p}=0.187)$; the body mass index (BMI) was considered eutrophic, $43.7 \%(\mathrm{n}=136)$ and $37.9 \%(\mathrm{n}=149)(\mathrm{p}<0.001)$. The pre- and postmenopause results showed differences regarding access to treatment, marital status, education, housing, first mammogram, alcohol and tobacco consumption, and BMI. Therefore, sociodemographic and lifestyle factors show a difference in patients with breast cancer in pre- and postmenopause.

Keywords: Breast Cancer; Lifestyle, Public Health. 